\title{
Author Correction: Lipid-droplet-accumulating microglia represent a dysfunctional and proinflammatory state in the aging brain
}

Julia Marschallinger, Tal Iram, Macy Zardeneta, Song E. Lee, Benoit Lehallier ${ }^{\mathbb{D},}$, Michael S. Haney, John V. Pluvinage, Vidhu Mathur, Oliver Hahn, David W. Morgens, Justin Kim, Julia Tevini, Thomas K. Felder $\mathbb{B}$, Heimo Wolinski,

Carolyn R. Bertozzi, Michael C. Bassik, Ludwig Aigner and Tony Wyss-Coray (1)

Correction to: Nature Neuroscience https://doi.org/10.1038/s41593-019-0566-1, published online 20 January 2020, corrected 31 January 2020.

In the version of this article initially published, errors occurred in Figs. 1k and 3b. In Fig. 1k, the percentages for the Ceramids (CE) groups were mistakenly included into the Other group; in Fig. 3b, the graph was inadvertently duplicated from Fig. 5h. The errors have been corrected in the HTML and PDF versions of the article.

Original
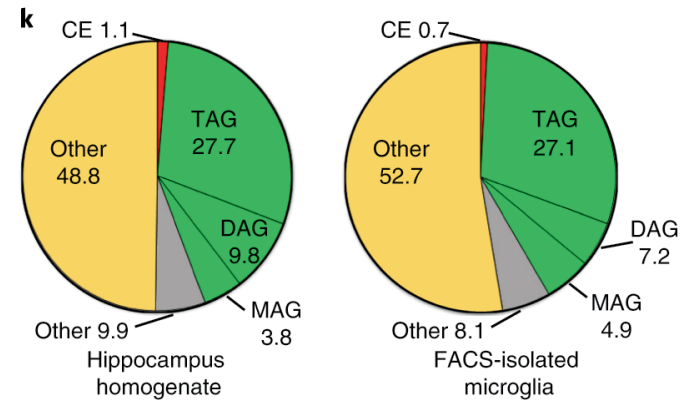

Corrected

k

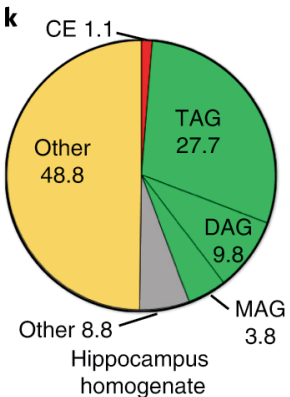

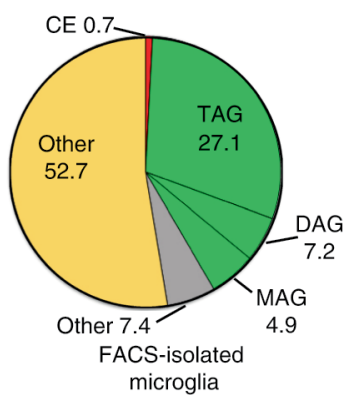

Fig. 1k | Original and Corrected.

Original

b

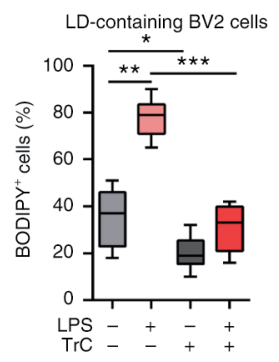

Corrected

b

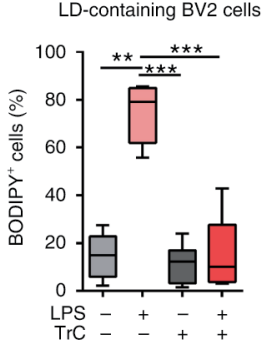

Fig. 3b | Original and Corrected.

Published online: 27 July 2020

https://doi.org/10.1038/s41593-020-0682-y

๑ The Author(s), under exclusive licence to Springer Nature America, Inc. 2020 